\title{
Perspectives on Nordic Working Life Research
}

\author{
I Jan Ch. Karlsson
}

U

elcome to this Thematic Issue on Perspectives on Nordic Working Life Research!

It is perhaps not that surprising that a journal called Nordic Journal of Work-

ing Life Studies contains many discussions about "Nordic Models": What is the Nordic Welfare State Model? What has happened to it lately? Is there still one? Has there ever been one? What about the Nordic Industrial Relations Model-is it on its way to be abandoned? And the Nordic Labor Market Model? Or the Nordic Work Environment Model? In contrast, in the Thematic Issue part of this issue of NJWLS Nordic working life research itself is discussed.

Editing the issue has led me to some (self)critical reflections on Nordic working life research-or perhaps rather reflections on the self-image of Nordic working life researchers. We often say that two of the cornerstones of Nordic working life research are the assumption that there is a positive correlation between employee autonomy at work and higher productivity, and that our research tradition is different from those found in other geographical areas (and, implicitly, probably better). Being part of the Nordic tradition, I too have claimed both, but I now think both needs to be qualified and critically discussed. Or rather, the first needs to be qualified and the consequences of the other critically evaluated.

It is clear from many studies that what employees most want in work is autonomy; it is equally clear that what employers want is high productivity. All too often we-that is, Nordic working life researchers-say that there is no contradiction involved here: If employees enjoy autonomy they will work more efficiently and productively. A work organization with autonomous workers (A) is a productive work organization (B). Our advice to practitioners therefore takes the form of an empirical generalization: Do A and B results. The qualification I suggest is that we should carefully consider the distinction between empirical and theoretical generalizations (Danermark et al. 2002, Ch. 4; Ackroyd and Karlsson forthcoming) in studies of organizations. In theoretical generalizations the concern is not empirical patterns but structures and their mechanisms, not "empirical regularities in patterns of events" (Sayer 2000: 146) but underlying mechanisms that produce empirical patterns.

Here is an example of an empirical generalization: In studies of people's orientations to work, a distinction is often made between instrumental and engaged attitudes. The instrumental means that one works only for the economic gain, while the engaged means that one (also) has reasons in work itself. In a questionnaire answered by a random sample of 1,482 Swedish employees in 2010, 64 percent reported that they held an instrumental attitude when they compared work with other parts of life, such as family, friends, and leisure (Eriksson et al. 2012). This empirical pattern can (within certain statistical limits) be generalized to the 4,048,000 employees that existed in Sweden at 
that time, claiming that "(about) 64 percent of Swedish employees in 2010 held an instrumental attitude to work.” The pattern found in the sample can, in other words, be generalized to the population from which the sample was drawn.

An example of a theoretical generalization: A market is a social structure which in its simplest form is made up of the internal relation between sellers and buyers of goods and services. One of the mechanisms that markets embody is that the sellers compete for customers. A basic theoretical generalization is, then, that "markets contain the mechanism of competition." A well-known empirical pattern which can result from the tendency of competition is that it leads companies to cut prices in order to attract more customers. We often hear that competition results in lower prices and that markets therefore are good in themselves for people. But this is not always the empirical result as the context of a specific market can contain other mechanisms which influence the empirical outcome. An example of such a pattern is that the number of companies diminishes through some of them driving other companies out of business, which in its turn likely leads to situations of oligopoly or even monopoly on the market, resulting in higher prices. The theoretical generalization "wherever there is a market there is the mechanism of competition" does not say anything about which empirical pattern will come about, as that is produced by the context of each empirical instance. For example, the price-reducing tendency can be weakened by the tendency to oligopoly, or the oligopolistic tendency can be blocked by laws forbidding such situations in a particular market.

Theoretical generalizations specify structures and their mechanisms and tendencies, but do not say anything about events and empirical patterns. Empirical generalizations specify the extent of certain events and empirical patterns, but say nothing about structures and their mechanisms and tendencies. Both are, of course, important in working life research-as in social science as such-but it should be noted that theoretical generalizations are more robust. The status of an empirical generalization is always doubtful: Does it hold tomorrow or did it hold yesterday? Does it hold for a different population? This doubt does not arise when it comes to theoretical generalizations. The social structure market has the same mechanisms and tendencies whether it exists in ancient Greece, medieval France, or Norway of today-if not it is not a market. Empirical generalizations say that "with probability $p$ the empirical pattern in sample $S$ at time $T$ can also be found in population $P$ at time $T$ "; theoretical generalizations say that "wherever structure $S$, there are mechanisms $M$ and tendency T." Thereby empirical generalizations cannot state anything about structures and mechanisms, while theoretical generalizations cannot state anything about events and empirical patterns.

My claim is now that we should be a little bit more cautious when we discuss the relation between worker autonomy and productivity by not saying "worker autonomy leads to higher productivity" but "there is a tendency for worker autonomy to lead to higher productivity." When empirical generalizations are generalized outside the cases in which they were originally formulated they become deterministic. The change in formulation implies, of course, that other mechanisms existing in or influencing the concrete workplace context can alter this empirical outcome. My experience is that we also do this when we do not make declarations about the grounds for Nordic working life research but give concrete advice to practitioners. Then we seldom say "do A and B will follow", but rather something like this (Pawson 2006: 100): 
"remember A"; "beware of B"; "take care of C"; "D can result in both E and F"; "Gs and Hs are likely to interpret I quite differently"; "if you try J make sure that K, L and M have also been considered"; "N's effect tends to be short lived"; "O really has quite different components - P, Q and R"; "and S works perfectly well in T but poorly for U”; (...) "little is known about $\mathrm{V}, \mathrm{W}, \mathrm{X}, \mathrm{Y}$ and $\mathrm{Z}$."

It is, I suggest, important that we as Nordic working life researchers reflect on our traditions, what we are doing, and what can be improved. The opening articles of this Thematic Issue greatly contributes to this end by carefully analyzing, first, characteristics of key contributions and, second, possible improvements of one of those contributions. The first article is Ole H. Sørensen and Peter Hasle's "Employees as individually and collectively acting subjects-key contributions from Nordic working life research." They claim that Nordic working life research has some special features-perhaps not unique, but still which differs from this type of research in other countries-and they try to define what characterizes this perspective. The authors discuss what they consider to be some of the classic key Nordic contributions by performing an historical analysis of this distinctiveness. The classics they have in mind are Lysgaard's book on the worker collectivity, socio-technical systems theory (e.g., Thorsrud), and theories about employees' control over and in work (e.g., Karasek and Gardell, respectively). They consider all three contributions mainly from the perspectives of collaboration between employers and employees, and employee influence at the workplace. A common denominator is found in that employees are regarded as active and reflexive subjects on both an individual and a collective level. Employees engage in their work not only to find meaning in it but also to contribute to the goals of the work organization. Sørensen and Hasle then compare this distinctive trait of Nordic working life research with some international research traditions within the field, namely labor process analysis (LPA), occupational medicine, and Human Resource Management (HRM). In a property space with the dimensions regarding employees as subject or object and as individuals or collectivities, they locate the traditions in this way: HRM regards employees as individual subjects; occupational medicine as individual objects; LPA as collective objects; and Nordic research as collective subjects. The conclusion is that this Nordic working life research perspective still provides a platform for research, although the Nordic model as such is under threat.

The second paper from within a Nordic working life research perspective is by Per Øystein Saksvik, Tove Helland Hammer, and Kjell Nytrø who contribute an article with the title "Social relations at the collective level: the meaning and measurement of collective control in research on the psychosocial work environment." Here Karasek's-and later Karasek and Theorell's-model of job demands, work control, and social support for judging qualities of the psychosocial work environment (PSWE) is at the center of interest. The authors argue that the model is in need of revision, turning the article into a methodological one with roots in the Nordic perspective discussed by Sørensen and Hasle. The most important dimension of the PSWE is, they claim, collective control in the form of workplace norms about social relations at the workplace. The point of departure for the argumentation is that the characteristics of the PSWE emerge from the social relations and processes between employees and managers. The norms of what is to be regarded as legitimate behavior are thereby at the center of the authors' attention. Further, it is important for the methodological aim that norms can be measured and be 
subjected to statistical modeling. In sum, the authors claim that social relations are an important, though often neglected, part of PSWE research and that organization and workplace norms are a form of collective control of employee and manager behavior tied to these relations. Being part of a collective context is a positive experience of importance for both the PSWE and the view of the conditions of employment. Compared with the common concept of social support in the Karasek and Theorell model, that of collective control is wider and of greater importance for research on PSWE according to the authors.

The next step after this theoretical argumentation is to reflect on the question how this concept can be measured. Here the authors suggest two principles: One is that the existing survey variables on the individual level should be complemented with ones on the collective level. Questions to respondents should, for example, not only take the form "Considering the work I do, I am fairly paid," but also "People who perform well are those who receive pay raises in this organization," thereby moving their frame of reference to a collective level. The second point is that the same type of data as from employees should also be collected from employers or managers. Discrepancies in the results between these two organizational actors indicate that there are problems in the PSWE.

My second (self)critical reflection concerns a possible consequence of our discussions about what specifically designates Nordic working life research compared with other research traditions. There is a tendency (note: tendency) to fencing ourselves in, to only take into account and refer to each other rather than to scholars and theories outside our region. Still, there are theories and research traditions on the other side of our enclosures that have clear similarities to Nordic working life research and which could help us improve our endeavors. Let me take an example (which I, of course, mention because I have tried to bring it to our attention before, see Karlsson 2008, 2012). There is a growing interest among Anglo-Saxon researchers in theories of dignity in and at work, as well as a wider analysis thereof in theories of the moral economy. To mention just a few important books and articles, Randy Hodson Dignity at Work; Sharon C. Bolton Dimensions of Dignity at Work; Bolton and Laaser "Work, Employment and Society through the Lens of Moral Economy"; Andrew Sayer Why Things Matter to People; and "Dignity at Work: Broadening the Agenda." Here we find analyses of what dignity in and at work means which are easy to recognize from Nordic research: The worker should have autonomy and a job that provides job satisfaction and is also meaningful, while at the same time giving the worker respect and opportunities for learning and development. Dignity at work means that there are structures and practices that give the worker a healthy work environment, just rewards, an individual and collective voice, job security, and equality of opportunity. But here are also insights that we seldom practice, namely that it is important to analyze the interplay between different dimensions of dignity:

Thinking in terms of dimensions allows for a detailed analysis of dignity at work that covers many important issues in the world of work and how experiences may differ. For example, many people enjoy dignity in work as they have some autonomy and/or meaning in the type of work they do, but not dignity at work in the sense that they do not enjoy good terms and conditions of employment. Yet others may carry out mundane and monotonous work but benefit from dignity at work in that they gain from a physically healthy working environment and secure terms and conditions. Combined, a dimensions of dignity model 
represents a useful opportunity for a holistic analysis of work in its blend of the inherent dignity of the human person with people management policies and practices that may either support or deny this human condition.

(Bolton 2010: 166)

In a wider meaning, working life can be seen through the lens of moral economy, in which the economy is regarded as embedded in social practices. Economic practices, such as employment, are always social relations fueled by norms and values. They can therefore be analyzed not only in terms of economic efficiency and productivity but also- or preferably-in the light of their consequences for human suffering and flourishing. In this case too, ideas like these are sometimes part of the Nordic working life research tradition, but usually without the same moral and ethical power in our theories. To my mind we could in addition do well in adopting some of the critical edge that this part of the international literature induces.

Two of the articles of this Thematic Issue consider how international research can improve Nordic working life studies. In the first one, Stine Jacobsen, Pia Bramming, Helle Holt, and Henrik Holt Larsen make a meta-study of international research perspectives in an article with the title "Quality in modern Nordic working life-investigating three related research perspectives and their possible cross-fertilization." The basic idea is that in people's working lives there are three life spheres of being, namely the individual entering an exchange relation with a work organization, the employee being part of the PSWE of a workplace, and the citizen engaging in working life politics. In combination the three spheres make up the individual's “overlapping working life” (OWL). Further, there are three research perspectives corresponding to the spheres: the individual HRM perspective, the employee work environment perspective, and the citizen welfare perspective. The ideal according to the authors is that research considers at least two-and preferably all three-perspectives simultaneously, that is, study OWL, as this can crossfertilize the impact of working life research. The character of the Nordic working life and welfare state makes it especially important to perform this kind of research here in order to improve the quality of working life.

The authors carry out an international literature review in order to find out to what extent combinations of the three perspectives occur. They follow a rather complicated screening and evaluation process of databases, seeking overlaps and cross-fertilization of the perspectives. Thereby the field is eventually narrowed down to only 24 publications, of which few take all three perspectives of OWL into account and some more a combination of two of them. After detailed investigations of these publications, the authors draw the conclusion that OWL is insufficiently analyzed in the international literature. Considering its special importance in the Nordic countries they recommend Nordic researchers to engage in studies of the full modern working life, that is, research covering the whole OWL.

The final article also argues that it would be fruitful for Nordic working life research to incorporate more of international perspectives. This suggestion is made by Paula Mulinari and Rebecca Selberg in their article "Intersectional directions in working life research-a proposal." The term intersectional emphasizes the importance of analyzing cross-cutting effects of the interaction of such social differentiations as gender, class, and ethnicity. The authors start out by noting the extent to which gender research historically has influenced working life research-especially perhaps in the Nordic countries. New 
types of studies, new perspectives, new theories—and new insights—entered the field. At the same time, they find that studies of working life have been important for the development of gender as well as intersectionality theories. They provide an historical account of the emergence and development of the intersectionalist perspective from an earlier analysis of gender, class, and ethnicity as separate and internally homogenous social categories to studying their interaction. Working life is shaped by classed, ethnicized, and gendered processes, while working life is an important arena for shaping these processes. Mulinari and Selberg's proposition is therefore to intensify the dialogue between working life research and gender research with intersectionality at its center. Nordic working life research has to a great extent taken gender into account but not so much intersectionality, while gender research on working life has not focused very much on its interaction with class and ethnicity.

Mulinari and Selberg give us some examples from the international literature which they say can be inspiring for Nordic working life research. One is Joan Acker's organization theory and especially her concept of "inequality regime" by which she means the ways in which class, gender, and ethnic inequalities are established and maintained. Another is Miriam Glucksman's notion of "Total social organization of labor," a complex and nested concept for simultaneous analyses of several different aspects of work. The authors' own example is both enlightening and surprising, namely breast-feeding. In sum, the article presents a strong appeal to Nordic working life researchers to intensify our dialogue with gender research. They present intersectionality as a proper bridge between these two fields, challenging the traditional inquiries and theories of both.

The four articles of this Thematic Issue may well be read together with two articles published in NJWLS Vol. 3, No. 1, 2013. One is written by Lena Abrahamsson and Jan Johansson entitled "One hundred years of inertia. An exposé of the concept of psychosocial work environment in Swedish policy and research.” They give us a short but comprehensive presentation of how PSWE has been understood in research and policy over 100 years, with Sweden as the focal point. Short, because they write in the format of an article. Comprehensive, because the authors take a broad understanding of the PSWE comprising both "health and illness," where factors as stress and burnout are central, "management and development," where employee involvement, learning, and innovation are central, and "problematization," which includes critically oriented research on the nature of work. The article not only provides an overview of the research that has been done in this area in the last 100 years. It also relates research to policy and practice. The article thus provides a valuable perspective on today's research and public debate on working life with a Nordic perspective.

The other has the title "Work environment dialogue in a Swedish municipalitystrengths and limits of the Nordic work environment model," authored by Kaj Frick. He has studied how the Nordic work environment model functions in the municipal sector, where unionization is high, trade unions appoint safety representatives, and dialogue between employee representatives and management on the working environment is well organized. Frick focuses on an ambitious project in a Swedish municipality, which should further improve the social dialogue about the work environment, while reducing absenteeism by 50 percent. The project's results were somewhat disappointing: The dialogue was improved ("How to do" was improved), but the practical efforts to improve the PSWE remained unclear ("what to do" remained unclear). It turned out that the local leaders had to find practical solutions of psychosocial problems and workload without having 
financial resources to make any difference and without being assigned to specific methods. The conclusion is therefore that the Nordic model is doing well-there are many meetings and dialogue. But the working environment is not doing so well. The social dialogue is not associated with "systematic work environment management."

Six articles making great contributions to Nordic working life research—enjoy!

\section{References}

Ackroyd, Stephen and Jan Ch. Karlsson (forthcoming) "Critical Realism, Research Techniques and Research Designs," in Paul Edwards, Joe O'Mahoney and Steve Vincent (eds.) Explaining Management and Organization Using Critical Realism: A Practical Guide. Oxford: Oxford University Press.

Bolton, Sharon C. (ed.) (2007) Dimensions of Dignity at Work. Amsterdam: ButterworthHeinemann.

Bolton, Sharon C. (2010) "Being Human: Dignity of Labor as the Foundation for the Spirit-Work Connection." Journal of Management, Spirituality and Religion, 7(2): 157-72.

Bolton, Sharon C. and Knut Laaser (2013) "Work, Employment and Society through the Lens of Moral Economy.” Work, Employment \& Society, 27(3): 508-25.

Danermark, Berth, Mats Ekström, Liselotte Jakobsen and Jan Ch. Karlsson (2002) Explaining Society. London: Routledge.

Eriksson, Birgitta, Jan Ch Karlsson and Tuula Bergqvist (2012) "Development of Work Orientations in Sweden,” pp. 126-38 in Bengt Furåker, Kristina Håkansson and Jan Ch. Karlsson (eds.) Commitment to Work and Job Satisfaction: Studies of Work Orientations. London: Routledge.

Hodson, Randy (2001) Dignity at Work. Cambridge: Cambridge University Press.

Karlsson, Jan Ch. (2008) Den smidiga mellanchefen-och andra motståndsberättelser. [The Agile Middle Manager—and Other Resistance Stories.] Malmö: Gleerups.

Karlsson, Jan Ch. (2012) Organizational Misbehaviour in the Workplace. Narratives of Dignity and Resistance. Basingstoke: Palgrave Macmillan.

Pawson, Ray (2006) Evidence-Based Policy. A Realist Perspective. London: Sage.

Sayer, Andrew (2000) Realism and Social Science. London: Sage.

Sayer, Andrew (2007) "Dignity at Work: Broadening the Agenda." Organization, 14(4): $565-81$.

Sayer, Andrew (2011) Why Things Matter to People. Cambridge: Cambridge University Press. 